\title{
Focus on Structural and Lexical Ambiguity in English Newspaper Headlines Written by Native and Non-Native Journalists: A Contrastive Study
}

\section{G.Khamahani}

\author{
Prof.Ilham M.Tahirov \\ Azerbaijan National, Academy Of Sciences, \\ Nesimi Institute of Linguistics \\ dr khamahani@yahoo.com +98-914-176-5980
}

\section{Doi:10.5901/mjss.2013.v4n6p379}

\begin{abstract}
Although ambiguity in languages is often considered as a problem, it provides value. Ambiguity is found in every aspect of language, but newspaper headlines are outstanding as the most important source of examples of ambiguity. One of the most important reasons that newspaper readers cannot be successful readers while glancing at newspaper headlines is that they are not aware of different types of ambiguities created by special characteristics which are typical of newspaper language. Ambiguity is not only typical of headlines, but in this research I deal with structural (noun-verb) and lexical (polyseme) ambiguity in English headlines written by native and non-native journalists. The hypothesis is that the texts, in the case of this study, the headlines written by native and non-native journalists contain different amounts of structural (noun/verb) and lexical (polyseme) ambiguity. In order to arrive at the exact amounts of the two above mentioned ambiguities, we made fifty tests of "Noun or Verb?" tests and fifty tests of "what does it mean?" tests based on the headlines in the two English newspapers written by non-native and foreign journalists. The participants were selected from the university undergraduate English students and described and compared the two sets of data in terms of structural and lexical ambiguities to find out which set of English newspaper headlines (written by native or non- native journalists) are more ambiguous. Finally we found out that headlines written by native journalists are more ambiguous both structurally and lexically. The outcomes of the study could be useful for all EFL learners and trainers. Furthermore EFL trainers can employ these findings when teaching Press Courses.
\end{abstract}

Keywords: structural ambiguity, lexical ambiguity, headline, textual genre

\section{Introduction}

A careful study of newspaper headlines reveals that a headline is an autonomous text which carries various functions within the newspaper's discourse and has specific features as regards language use (Reah, 1991). This brief explanation implies that understanding headlines is sometimes equals understanding the whole text. It is thought that the textual genre of newspaper headlines including syntax, semantics and stylistics is a hurdle to understanding while leading to misinterpretations (Hobbs, 1998). It is not clear whether the degree of difficulty is the same for university students when dealing with English newspaper headlines written by native and non-native journalists. Among the three aspects of textual genre of newspaper headlines, the study aims at finding out the ratio of the influence of syntax and semantics on the two sets of headlines. This ultimately leads to finding out the ratio of the two aspects of textual genre of newspaper headlines and their influence on arriving at wrong and usually humorous interpretations. In order to study newspaper headline, the study was confined to only ambiguity which is the main concern of all three aspects of the textual genre of newspaper headlines. One of the most serious problems of foreign language learners is how to arrive at the central meaning of newspaper headlines. Despite the fact that ambiguity in language is an essential part of language, it is often an obstacle to be ignored or a problem to be solved (Hoefler, 2003) for people to understand each other. University students are often garden- pathed when reading newspaper headlines or unable to understand the intention of the writer. This seems to be due to the different ambiguities made by the intention of the journalist.

\section{The Purpose of the Study}

The main purpose of the present study is to arrive at the ratio of lexical (polyseme) ambiguity and structural (noun/verb) 
ambiguity in newspaper headlines written by native and non-native journalists. Finally pedagogical implications for teaching reading newspaper in conjunction with this study will be discussed.

\section{The Significance of the Study}

So far, no contrastive study concerning ambiguity in newspaper headlines written by native and non-native journalists has been done. It is worth to mention that a few studies concerning intertextuality, stylistics, pragmatics, reported speech, etc. have been done recently. But all these studies have tried to characterize the textual genre and individual features of two specific newspapers in a certain country. Inspired by current works done in this field, this study tries to provide some guidelines for the realization of ambiguous newspaper headlines.

\section{Research Question and Hypothesis}

This research intends to arrive at the ratio of structural (noun/verb) ambiguity and lexical (polyseme) ambiguity in newspaper headlines written by native and non- native journalists. We wonder whether university students make the same degree of mistakes when reading newspaper headlines in the two sets of newspapers.

\section{Review of the related literature}

Clare (1993) believes that something is ambiguous when it is understood in two or more possible senses or ways. If ambiguity is in a word, it is called lexical ambiguity, in a sentence or clause, structural ambiguity. Rusche (1980) proposes that ambiguity should be extended to any verbal nuance, which gives room to alternative reactions to the same linguistic element. Hoefler (2003) contends that ambiguity means there is more than one meaning assigned to the same single. If this results from a compositional grammar, i.e. if a complex single can be parsed in more than one way, we end up whit syntactic ambiguity. Smith (1995) argues that if ambiguity in a sentence is caused by the existence of homophonous words (words sounding the same) or polysemous words (words having more than one related meaning), it is called lexical ambiguity. And structural ambiguity is the result of the two sentences having the same linear order of constituents but a different structure. Beaver (2004) believes that words are stored in a mental dictionary or (lexicon). Some words have more than a single meaning. The result is lexical ambiguity. He believes that sometimes the same sequence of words can be structured in more than one way, giving rise to more than one meaning. And the result is syntactical or structural ambiguity. Chantree (1994) maintains that the basic definition of ambiguity, as generally used in natural language processing, is capable of being understood in more than one way. It can be classified into many different types and using various different classification schemes. The most widely used classification is probably the one which divides ambiguity into lexical ambiguity, where several interpretations result from the different ways in which the meanings of words in a phrase can be combined; syntactic ambiguity, where several different interpretations result from the different ways in which a sequence of words can be grammatically structured; and pragmatic ambiguity where the context of a phrase results in there being alternative interpretations of that phrase.

Semantic ambiguity depends on the meaning of a word or words which themselves can be misinterpreted.

\section{Participants}

In order to carry out the study, we gave a test from $35 \mathrm{~B}$. A students of Tabriz Teacher Training University who had passed press course or were studying it that semester. We made sure that all these participants had interaction with reading headlines and asked their ideas about the ambiguity of headlines. All of them stated that they had already had difficulty understanding the intent of the writer as a result of some characteristics which are typical of news headlines.

\section{Instrumentation}

To carry out the research, fifty structurally ambiguous headlines used in both newspapers and fifty polysemously ambiguous newspaper headlines were selected. We gave a test from university students who had passed Press Course. Previously headline ambiguity were discussed and analyzed. The methodology of the present study will be introduced making clear the way our data will be analyzed. Furthermore the purpose and the research question are restated, and 
the significance of the study is reviewed. And then the anticipatory data of the study is introduced, and finally the method of data analysis is explained.

\section{Design and methodology}

As the study deals with contrasting two groups of newspaper headlines in terms of lexical and structural ambiguity, the design appropriate to the study will be the analysis of the ambiguous newspaper headlines based on the tests taken by university students on two sets of data. Fifty newspaper headlines in the two newspapers written by non-native and native journalists which were structurally ambiguous were selected. A test was given on the basis of the previously selected headlines. In addition, fifty semantically ambiguous headlines (polysemes) were selected and a test was given on the prepared headlines. Finally, determining the comparative influence of structural and lexical ambiguity on the comprehension of headlines is focused on. The methodology of this research is based on an article got from the internet which reviewed different kinds of ambiguities (including noun/verb, homoneme, P.P attachment, anaphoric, multiple, metaphoric and lexical ambiguity) while giving interesting linguistic descriptions for each of them. The writer gave only linguistic descriptions, but here, in this study, structural ambiguity (noun/verb) ambiguity and lexical ambiguity (polyseme ambiguity) will be analyzed comparatively and contrastively. Among different types of ambiguity described by the article mentioned above, noun/verb and polyseme ambiguities were the most problematic ones. In order to have sufficient data for analysis, we selected:

- 50 headlines written by native journalists based on noun-verb ambiguity;

- 50 headlines written by non-native journalists based on noun-verb ambiguity;

- 50 polysemously ambiguous newspaper headlines written by native journalists;

- 50 polysemously ambiguous newspaper headlines written by non-native journalists.

It's mentionable that noun/ verb ambiguous headlines were tested based on "Noun or Verb?" method and polysemously ambiguous headlines were tested based on «what does it mean?" method .In order to clarify the subject in question, it seems necessary to elaborate on Noun/Verb and Polyseme ambiguity.

Noun- verb ambiguity: Sometimes noun/verb ambiguity leads to two different kinds of interpretations by which two different deep structures are created in the reader's mind. Here is an example from native newspaper headlines: "Eye drops off shelf" Is" drops" $\mathrm{N}$ or V? It can be argued that considering "drops" as a verb can lead to this interpretation: Eye was already on the shelf .By considering "drops" as a noun (plural), we interpret the headline as: Eye drops are off shelf. We can conclude that sometimes noun/verb ambiguity leads to a false and usually humourous interpretation.

Polyseme Ambiguity. Sometimes polysemous words lead to an unusual and humourous interpretations. Polysemous words have the same spelling and pronunciation but two or more different meanings. Here is an example from native newspaper headlines: "Iraqi head seeks arms". It can be argued that the unusual juxtaposition of two polysemous words lead to two interpretations: by considering "head" (meaning chief) and "arms" (weapons), there is no ambiguity. But by considering head (meaning the top part of body) and arms (meaning body parts), we will absolutely face this unusual and humourous interpretation: "The head of an Iraqi troop has lost his arms and is looking for them in order to have them attached." The data are going to be analyzed in terms of the degree of the influence of these two ambiguities on the interpretation of the university students.

\section{Data Source}

Two types of newspaper headlines written by non-native writers (Iran Daily) and those written by native writers (Washington Times) are selected based on noun/verb ambiguity and polysemy ambiguity. The following table shows the source of the headlines:

\begin{tabular}{|l|l|c|c|}
\hline Source & Publisher & Publication Date & $\begin{array}{c}\text { Number of Chosen } \\
\text { Newspaper Headlines }\end{array}$ \\
\hline $\begin{array}{l}\text { Iran Daily } \\
\text { Newspaper }\end{array}$ & www.IranDaily.com & July 2012 & 100 \\
\hline $\begin{array}{l}\text { Washington Times } \\
\text { newspaper }\end{array}$ & www.WashingtonTimes.com & July 2011 & 100 \\
\hline
\end{tabular}

Table 1: Data Source, Publisher, Publication Date, and Number of chosen Newspapers from Each Source. 


\section{Data Analysis}

The following table represents the percentage of true and false answers based on the test taken by university students. (Newspaper headlines written by non-native journalists)

\begin{tabular}{|l|c|c|}
\hline \multicolumn{1}{|c|}{ Percentage } & $\begin{array}{c}\text { Percentage of True } \\
\text { Answers }\end{array}$ & $\begin{array}{c}\text { Percentage of False } \\
\text { Answers }\end{array}$ \\
\hline Noun-Verb Ambiguity & $\% 69$ & $\% 31$ \\
\hline Polyseme Ambiguity & $\% 34$ & $\% 66$ \\
\hline
\end{tabular}

Table 2: The Percentage of True and False Answers in Iran Daily Newspaper Headlines

In this table, the first column shows the different ambiguities. The second column indicates the percentage of true answers and the third one shows the percentage of false answers. Now we want to show the above mentioned features in English newspaper headlines written by native journalists in the following table.

\begin{tabular}{|l|c|c|}
\hline \multicolumn{1}{|c|}{ Percentage } & $\begin{array}{c}\text { Percentage of True } \\
\text { Answers }\end{array}$ & $\begin{array}{c}\text { Percentage of False } \\
\text { Answers }\end{array}$ \\
\hline Noun-Verb Ambiguity & $\% 53$ & $\% 47$ \\
\hline Polyseme Ambiguity & $\% 32$ & $\% 68$ \\
\hline
\end{tabular}

Table 3: The Percentage of True and False Answers in Foreign Newspaper Headlines.

And this table shows the same features with respect to newspaper headline written by native journalists. Comparing the two tables shows the coordination between the features on question in the two different newspapers.

\section{Conclusions of the Study}

This study have been mainly concerned with only the amounts of structural (noun/verb) ambiguity and lexical (polyseme) ambiguity in newspaper headlines without entering into different kinds of ambiguity found everywhere in language. On the basis of the current theories and studies on the concept of ambiguity, we developed different tests on headlines based on structural and lexical ambiguity in newspaper headlines. According to our data analysis, the amounts of both lexical and structural ambiguity in foreign newspaper headlines are higher in comparison to the amount of those two kinds of ambiguity in newspaper headlines written by non-native journalists. One can make the conclusion that, on the whole, the headlines written by native journalists are more ambiguous than those headlines written by non- native journalists. We can use the results to make some pedagogical implications for reading newspaper headlines. And the separate study of some headlines will give us some guidelines which seem necessary for university students who take press courses or to everyone who come across a newspaper headline in everyday life.

\section{Pedagogical Implications and Discussion}

As argued by many authors, ambiguity can be found everywhere in language and is usually difficult to understand. Clare (1993) suggests that " ... ambiguity is an obstacle to be ignored or a problem to be solved for people to understand each other." Kevin (1998) believes that there is a direct relationship between vision and cognition with respect to newspaper headlines. It is suggested that headline readers should first pay attention to the structure of the newspaper headlines. In order to avoid wrong interpretations, as this research shows, the amount of structural ambiguity is not the same in the two sets of headlines, more in foreign newspaper headline. so it requires students and readers to be more attentive to the structure of foreign newspaper headlines in order to avoid arriving at ambiguous and usually humourous interpretations. According to the results of our study, ambiguity is not only limited to structural ambiguity. Lexical ambiguity is another problem of which English trainers should make their students aware. In the case of our study, polyseme ambiguity is a hurdle for understanding the intent of the writer because the frequent use of polysemous words is more attention- catching. As this research shows the amount of lexical (polyseme) ambiguity is not the same in the two 
sets of headlines, more in foreign newspaper headlines. This implies that foreign writers use more words in their literary terms with their wider ranges of meaning. So headline readers should be aware of the difference between writing styles of headlines.

The careful study of some specific headlines based on true and false answers shows that the structural ambiguity is very serious in terms of nominalization, especially in subject positions. This fact implies that nominalization is an important factor leading to wrong interpretations in both of the two sets of newspaper headlines. The careful study of data based on some other specific headlines reveals the fact that verbless headlines written by non-native journalist are noticeably more structurally ambiguous. Interestingly, the amounts of structural ambiguity in those headlines including double ambiguity are almost equal in the two sets of newspaper headlines. Another look at the answers shows that nonnative university students don't pay any attention to the context in which a word is included and ultimately this fact leads to making wrong interpretations when glancing at newspaper headlines. Finally, similar studies can be carried out to measure the amounts of ambiguity in other dimensions (figurative ambiguity, homonym ambiguity, intertextuality, anaphoric ambiguity, stylistics, reported speech, metaphoric ambiguity, etc). These headlines were selected from native and non- native newspapers. In an alternative study, one could choose headlines from different kinds of newspapers written by either native or non-native journalists.

\section{References}

Abastad, C., 1980, Discourse of Headlines, An Article on the Internet.

Atherton C., 1993, The Stoics on Ambiguity, Cambridge University Press, 1993.

Beaver D., 2004, Ambiguity and Diagnostic Tests, Stanford University, winter, 2004.

Chantree F., 1994, Ambiguity Management, The Open University, 2003.

Clare C., 1993, Language Ambiguity: A Curse and a Blessing, volume 7, No.1, January 2003.

Develotte c., 1990, Discourse Analysis of Newspaper Headlines, University of Sydney, Australia, 2003.

Kevin P., 1998, Vision and Cognition, An Article on the Internet.

Ebrach G.,1997, Ambiguity and Linguistic Preferences, University of Saarlandes, 1992.

Fijck V., 1990, The Logic of Ambiguity, An Article on the Internet.

Hobbs. S, 1998, Figurative (Metonymic or Metaphoric) Ambiguity in Newspaper Articles and Other Texts, Canada.

Hobbs, J. R., 1995, Computers and Language, An Article on the Internet.

Hoefler S., 2003, Syntactic Ambiguity, University of Zurich, October 2003.

Hoenisch. S., 1996, Ambiguity and Computational Linguistics, AnArticale on the Internet.

Jalilnejad A., 2002, Reading Newspaper Headlines, Jungle Publication, Isfahan.

Kamsties. E., 2001, Surfacing Ambiguity, PhD Thesis, Kaiserslautern, Germany, 2001.

Lewis. R.L., 1994, Computational Psycholinguistics, Macmillan Reference Ltd.

Long D. "polysemy" An Article on the Internet.

Miller S., 2001, Ambiguous Words, imp magazine, 2001.

Pearce D., 2005, Lexical Tuning, Sussex University, 2005.

Power, M., 1998, Computing Ambiguity, An Article on the Internet.

Reah. D, 1991, The Language of Newspapers, Routledge, London, 2002.

Rusche H., 1998, "Ambiguity", English Department, Emory.

Smith K., 1995, language Ambiguity, An Article on the Internet

Sokouti S., 2003, Headlines of Newspapers.

Shams, M. R., 2001, Practice with Newspapers, Jungle Publication, Isfahan.

Sharniak E., 1993, Semantic Ambiguity, An Article on the Internet.

Shemtov H., 1997, Ambiguity and Natural language Generation, PhD Thesis, Washington University.

Sproat R., 1990, Introduction to Computational Linguistics, An Article on the Internet, 2003.

Swiny D., 1970, Factors of Ambiguity, An Article on the Internet.

Stevenson M., 1993, Polysemous Word, An Article on the Internet.

Tahririan M.H., Reading Journalistic English, Tehran, Payame Noor University.

Willemes S., 2001 Solving Ambiguity, An Article on the Internet. 
